\title{
A simple diagnostic milk medium for Pseudomonas aeruginosa
}

From the Pharmaceutical Microbiology Group, School of Pharmacy, Bath University of Technolog $\overrightarrow{9}$, Bath, Somerset, England

SYNOPSIS An agar medium containing $10 \%$ defatted milk has been tested as a diagnostic medium for Pseudomonas aeruginosa and, in particular, for differentiating between $P$. aerugino $\$ 2 a$ and $P$. fluorescens. Only $P$. aeruginosa colonies gave clear zones due to hydrolysis of case $\frac{\Gamma}{\mathrm{T}}$ together with diffused green pigment. Results on milk agar correlated well with the pattern $\vec{\theta}$ results from a variety of conventional tests used to identify this organism. Pigment production of $P$. aeruginosa on milk agar was better than on special media commonly used to enhange this characteristic. Routine diagnosis of $P$. aeruginosa is recommended by streaking on a sol medium containing $10 \%$ defatted milk granules, $25 \%$ nutrient broth, and $2 \%$ agar, ahid examining for clear zones and pigment after 24 hours' incubation.

The genus Pseudomonas is a group of aerobic, Gram-negative, motile rods that are catalaseand oxidase-positive as well as attacking sugars oxidatively without producing gas. In addition diffusible yellow or green pigments may be produced. Identification of this genus (the pseudomonads) depends on the pattern of results from a series of tests to establish these characters (Cowan and Steel, 1965). In addition, only some pseudomonads are pigmented, and in pigmented species there are some non-pigmented strains. Many methods for the enhancement of pigment production have been described and analysed (Colwell, 1964), and, although together they may be useful, none is specific on its own.

Several tests have been proposed as specific for $\boldsymbol{P}$. aeruginosa (Haynes, 1951; Gaby and Free, $1953 ; 1958)$, but it is generally agreed that in order to distinguish conclusively between the so-called fluorescent aerobic pseudomonads, ie, between $P$. aeruginosa, $P$. fluorescens, and $\boldsymbol{P}$. putida, a study of such tests as those already quoted, and others similar, is necessary. Unless $P$. aeruginosa produces pyocyanine (or pyorubin) pigments its identification is often difficult and may necessitate the use of a whole battery 委 tests (Rhodes, 1961; Colwell, 1964). Phillips (1969) has proposed a series of nine tests for the identification of $P$. aeruginosa from clinicis material. Stanier, Palleroni, and Doudoroff (196) have shown that the determination of the nutotional spectra is probably the most useful methơd available at the moment for practical taxonomic purposes, but that even this represents only first approximation towards characterizing the phenotypes of the aerobic pseudomonads.

Routine use of an agar milk medium has proved valuable in confirming the presence of $P$. aer ginosa, colonies of which showed a clear zordo due to hydrolysis of casein, together with grees pigment that diffused into the medium. This paper reports on a number of strains of the three species within the fluorescent aerobic pseudomonat cluster grown on several such milk media, with a view to its use as a diagnostic medium for $P$. aeruginosa.

Materials and Methods

ORGANISMS

Table I lists the organisms used. 


\begin{tabular}{|c|c|c|c|c|c|}
\hline \multicolumn{3}{|c|}{ Pssudomonas aeruginosa } & \multicolumn{2}{|c|}{$\begin{array}{l}\text { Pseudomonas } \\
\text { fluorescens }\end{array}$} & \multirow{2}{*}{$\begin{array}{l}\text { Pseudomonas putida } \\
\text { Lab. stock strain-source } \\
\text { unknown }\end{array}$} \\
\hline CST & 651 & Path. lab. faeces sample & NCIB & 3756 & \\
\hline CST & 652 & Path. lab. faeces sample & NCIB & 8248 & \\
\hline CST & 653 & Path. lab. infected ear & NCIB & 8251 & \\
\hline CST & 654 & Path. lab. faeces sample & NCTC & 8248 & \\
\hline CST & 655 & Path. lab. & NCIB & 8249 & \\
\hline OSU & 64 & From Dr R. G. Eagon ${ }^{1}$ & NCIB & 8729 & \\
\hline NCTC $^{2}$ & 6750 & & NCIB & 8865 & \\
\hline NCTC & 7244 & & NCIB & 8729 & \\
\hline NCTC & 8203 & & NCIB & 9033 & \\
\hline NCTC & 1999 & & NCIB & 9046 & \\
\hline NCTC & $6751^{3}$ & & NCIB & 9494 & \\
\hline NCTC & $5940^{3}$ & & & & \\
\hline NCTC & $950^{3}$ & & & & \\
\hline NCTC & $8505^{3}$ & & & & \\
\hline CST & 656 & $\begin{array}{l}\text { Path. lab. Post mortem- } \\
\text { infant }\end{array}$ & & & \\
\hline $\mathrm{NCIB}^{4}$ & 5940 & & & & \\
\hline NCIB & 8295 & & & & \\
\hline NCIB & 8626 & & & & \\
\hline CST & 657 & $\begin{array}{l}\text { Contaminated distilled } \\
\text { water Bath University }\end{array}$ & & & \\
\hline
\end{tabular}

Table I Organisms used in diagnostic tests

${ }^{1}$ Kindly supplied by Dr R. G. Eagon, University of Georgia, Athens, GA, USA

${ }^{2}$ National Collection of Type Cultures, Central Public Health Laboratory, Colindale Ave, London, NW9, England

${ }^{3}$ These organisms were kindly given by DrS. P. Lapage, Curator of the National Collection of Type Cultures, as examples of $P$. aeruginosa which are poor pigment producers

'National Collection of Industrial Bacteria, Torry Research Station, Aberdeen, Scotland

MEDIA

Yeast extract broth was used throughout this study (Rhodes, 1959). When solid media were required for plating, $2 \% \mathrm{w} / \mathrm{v}$ New Zealand agar was dissolved in the yeast extract broth.

A $20 \%$ solution of either defatted skim milk powder (Oxoid) ${ }^{1}$ or Marvel (Cadburys) ${ }^{2}$ defatted milk granules was prepared, and autoclaved for five minutes at $115^{\circ} \mathrm{C}$. Equal volumes of sterilised $4 \%$ solution Bacto agar (Difco) ${ }^{3}$ and milk solution were mixed at approximately $60^{\circ}$ and $15 \mathrm{ml}$ plates immediately poured. The plates were oven dried at $37^{\circ} \mathrm{C}$ for one hour before use.

GRAM REACTION

Microscopic examination of a modified Gramstained smear (Preston and Morrell, 1962) of a culture grown on yeast extract agar was performed to study the Gram reaction.

\section{MOTILITY}

Motility was evaluated by microscopy of a hanging drop. extract agar. A rapid and ebullient evolution $\triangle$ of gas (oxygen) was taken as evidence of the $\overline{\bar{F}}$ presence of catalase.

OXIDASE TEST

The Rogers (1963) modification of the Kovacs(1956) method was used with colonies grown on yeast extract agar.

OXIDATION/FERMENTATION TEST The method of Hugh and Leifson (1953) was $\vec{\circ}$ used.

OTHER TESTS

Other tests to distinguish between species $\stackrel{N}{\omega}$ in the fluorescent cluster of the aerobic pseudo- ? monads (Stanier et al, 1966) were as follows.

\section{Growth temperatures}

Growth was investigated at temperatures of 42,3 37,22 , and $4^{\circ} \mathrm{C}$, by inoculating $5 \mathrm{ml}$ volumes of $\frac{\varrho}{3}$ yeast extract broth maintained at the stated $\stackrel{\rho}{\supset}$ temperature to within $\pm 0.5^{\circ} \mathrm{C}$ in a water bath. $\vec{\varphi}$ Tubes were examined daily for seven days to $\partial$ determine if growth had occurred.

\section{Gelatin hydrolysis}

Nutrient gelatin (Oxoid) was inoculated with a wire stab in $20 \mathrm{ml}$ volumes in McCartney bottles. $\frac{\Phi}{\perp}$ The containers were incubated at $22^{\circ}$ for seven $\vec{F}$ days. Those showing growth down the line of $\frac{0}{3}$ inoculation and no liquefaction were recorded $\frac{}{J}$ as negative, those showing growth with liquefaction of the medium were recorded as positive, and those showing no growth were recorded 0 accordingly.

\section{Production of pyocyanine}

Pyocyanine production on King's medium A, (King, Ward, and Raney, 1954) and the Tween 5 medium of Wahba and Darell (1955) was tested $\frac{D}{O}$ by streaking 18 -hour cultures on to 20 -ml plates and incubating for 48 hours at $37^{\circ}$ and $22^{\circ} \mathrm{C}$. N

\section{Gluconate utilization}

The method of Haynes (1951) was used, modified by the use of Clinistix ${ }^{4}$, to detect the presence of the oxidized product, 2-keto-gluconate, as reducing substances, shown to be absent by testing the medium before inoculation (Cowan and Steel, 0 1965). Slime production was also tested for by the general appearance of the medium after five $\stackrel{\Phi}{\Phi}$ days' growth, at $37^{\circ} \mathrm{C}$, and by the 'reverse swirl $\mathbb{\Phi}$ test' (Haynes, 1951).

Oxo Ltd, Thames House, Queen Street Place, London, EC4

${ }^{2}$ Cadbury Bros Ltd, Bournville

Difco Laboratories, Detroit 1, Michigan, USA

Ames \& Co. Ltd, Stoke Poges, Bucks. 


\begin{tabular}{|c|c|c|c|}
\hline Test & P. aeruginosa & P. fluorescens & $\mathbf{P}$ putida \\
\hline Growth at $4^{\circ} \mathrm{C}$ & - & + & $\mathrm{v}$ \\
\hline Growth at $22^{\circ} \mathrm{C}$ & + & + & + \\
\hline Growth at $37^{\circ} \mathrm{C}$ & + & + & - \\
\hline Growth at $42^{\circ} \mathrm{C}$ & + & - & - \\
\hline $\begin{array}{l}\text { Gelatin hydrolysis } \\
\text { Production of }\end{array}$ & + & $\mathrm{v}$ & - \\
\hline & + & - & - \\
\hline $\begin{array}{l}\text { gluconate to } \\
\text { 2-keto-gluconate }\end{array}$ & + & + & $\mathbf{v}$ \\
\hline Slime production & + & $\mathrm{v}$ & $\mathbf{v}$ \\
\hline $\begin{array}{l}\text { Utilization of } \\
\text { acetamide }\end{array}$ & + & - & $\mathbf{v}$ \\
\hline $\begin{array}{l}\text { Utilization of } \\
\text { geraniol } \\
\text { Utilization of }\end{array}$ & + & - & - \\
\hline $\begin{array}{l}\text { Utilization of } \\
\text { trehalose }\end{array}$ & - & + & - \\
\hline $\begin{array}{l}\text { Utilization of } \\
\text { inositol } \\
\text { Utilization of }\end{array}$ & - & + & - \\
\hline $\begin{array}{l}\text { sucrose and levan } \\
\text { formation }\end{array}$ & - & + & - \\
\hline $\begin{array}{l}\text { Utilization of } \\
\text { benzylamine } \\
\text { Utilization of }\end{array}$ & - & - & + \\
\hline creatine & - & - & + \\
\hline
\end{tabular}

Table II Differentiation between $\mathbf{P}$. aeruginosa, $\mathbf{P}$. fluorescens, and $\mathrm{P}$. putida on the basis of the tests described

$$
\begin{aligned}
& +=\text { more than } 90 \% \text { of strains positive } \\
& \bar{v}=\text { less than } 10 \% \text { of strains positive } \\
& v=\text { variable }
\end{aligned}
$$

\section{Utilization of various carbon sources}

Stanier et al (1966) have stated that the nutritional spectra of this group probably forms one of the most satisfactory taxonomic methods for differentiating between $P$. aeruginosa and $P$. fluorescens. Accordingly we have selected those characters that give the greatest degree of differentiation. Using the method of Stainer et al (1966), the ability of the organisms to utilize acetamide, geraniol, trehalose, inositol, sucrose (levan formation), benzylamine, and creatine was tested.

The reactions to each of these tests are summarized in Table II.

\section{Growth on skim milk agar}

The main purpose of this study was to determine if growth, pigment production, and caseinase production on milk agar could be used to differentiate between $P$. aeruginosa and other related fluorescent aerobic pseudomonads. Accordingly, milk agar plates were streaked with the organisms listed, and incubated at $37^{\circ}$ for 48 hours. Growth, pigment production, and hydrolysis of the milk, as shown by clear transparent zones surrounding the areas of growth, were all recorded separately.

One disadvantage of the simple milk agar is that it takes $\mathbf{4 8}$ hours for full pigmentation and hydrolysis to show. Varying amounts of Oxoid nutrient broth no. 2 were added to the milk to determine if the incubation time could be reduced.

Colony counts of a suspension of $P$. aeruginosa were performed in quintuplicate on agar plates prepared from $100 \%$ nutrient agar, $75 \%$ nutrient agar $+25 \%$ milk agar, $50 \%$ nutrient agar $+50 \%$ milk agar, $25 \%$ nutrient agar $+75 \%$ milk $?$ agar, and $100 \%$ milk agar. Twenty-ml plates were poured and oven dried for two hoursu at $37^{\circ} \mathrm{C}$, and $0.5 \mathrm{ml}$ aliquots of an appropriate dilution of a 24-hour broth culture of $P$. aerugi nosa NCTC 6750 in sterile nutrient broth wer $\overrightarrow{\vec{F}^{2}}$ spread on the surface with a wire spreader Colonies were counted after $\mathbf{4 8}$ hours' incubations at $37^{\circ} \mathrm{C}$.

\section{Results}

\section{IDENTIF IC A TION}

Cowan and Steel (1965) define the genus Pseudo monas in the following terms: Gram-negativ\& rods, motile, aerobic, catalase positive, oxidase positive, attack sugars by oxidation, but do not produce gas, and diffusible yellow-green pig స ments may be produced. Their scheme of identio fication has been followed, with the addition of tests designed to distinguish between $P$. aerus ginosa and $P$. fluorescens with greater precision

All of the organisms tested conformed to thi description. The results of the other tests were interpreted in a manner similar to that of Cowas and Steel (1965), and, on this basis, the three species under investigation were separated (Table II).

\section{GROWTH TEMPERATURE}

Growth, where it occurred, was nearly always clearly visible, but comparison was always made with a tube of inoculated yeast extract brote incubated at the same temperature for seven days. Where growth was doubtful or scant, $\frac{8}{8}$ replicate tube was re-inoculated, and incubated for a further seven days.

Growth tests at $22^{\circ} \mathrm{C}$, in addition to the thres other usual temperatures, were carried out as control for gelatin liquefaction, since reading of these results is easier if the gelatin is not allowe to melt.

Where no growth was present, particularly at $4^{\circ} \mathrm{C}$ when growth is to be expected to proceed much more slowly, tubes were returned to the water bath for a further seven days before negative was finally recorded.

\section{GELATIN HYDROLYSIS}

Gelatin hydrolysis, as evidenced by liquefactiono of the nutrient gelatin around the area of growt down the stab, was easy to see when it occurre

PRODUCTION OF PYOCYANINE

Pyocyanine, the blue-green pigment that characteristic of most strains of $\boldsymbol{P}$. aeruginosa, enhanced on various special media. Both King A medium (King et al, 1954) and the Tween 


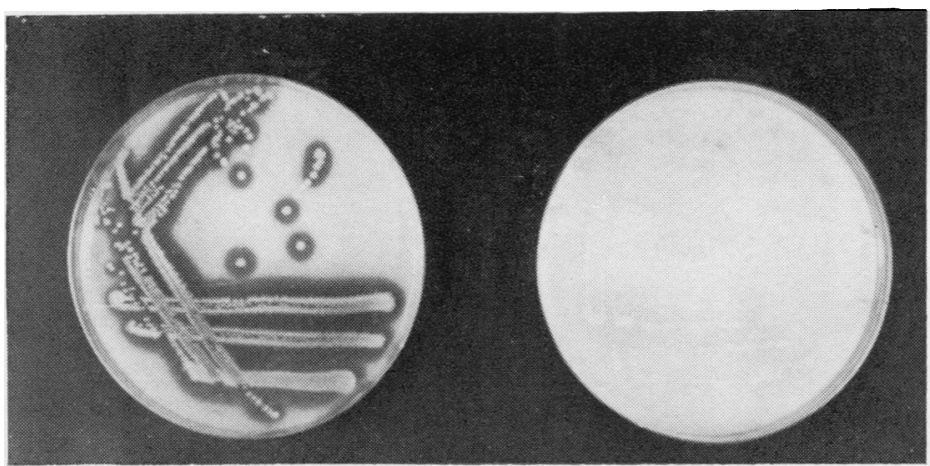

Fig. Appearance of (left) P. aeruginosa, and (right) P. fluorescens after incubation of milk agar.

80 medium of Wahba and Darell (1965) are reported to give good pigment production, with otherwise non-pigmented varieties. All but three of the strains of $\boldsymbol{P}$. aeruginosa tested produced pyocyanine equally well on both these media.

\section{GLUCONATE UTILIZATION}

The utilization of gluconate, and its conversion to 2-keto gluconate with the production of slime, has been used as a method for differentiation between $P$. aeruginosa and $P$. fluorescens (Haynes, 1951). Although all strains of $P$. aeruginosa produce both slime and keto-gluconate from this source, we have found that production of slime is not a reliable guide on its own. The presence of reducing compounds in the medium after growth in addition to the slime has been found to give far more reliable results than the measurement of slime production alone.

UTILIZATION OF VARIOUS CARBON SOURCES The determination of the nutritional spectra has been advocated by Stanier et al (1966) as a method for differentiating between members of the genus Pseudomonas. The specificity of this method has been substantiated in this study, but the method is tedious and not well suited for day-to-day routine use. It will only work reliably when several different carbon sources are used to determine the pattern, and also if the method described is carried out exactly with due care and attention to all details.

\section{GROWTH ON MILK AGAR}

The main purpose of this study was to ascertain if this simple medium might have a use in distinguishing between $\boldsymbol{P}$. aeruginosa and related species, especially $\boldsymbol{P}$. fluorescens. All the strains shown to be $P$. aeruginosa as a result of the previous tests gave a typical reaction on milk agar when incubated for 48 hours at $37^{\circ} \mathrm{C}$. Pigment production was as good, if not better than on those media specifically designed to demonstrate pyocyanine pigment. It was bright green, and diffused throughout the whole of the plate. In addition, the presence of extracellular $\vec{\sigma}$ proteinase was demonstrated by the hydrolysis of milk protein as shown by a clear transparent $\overrightarrow{\overrightarrow{\vec{S}}}$ zone surrounding the colonies (Figure). Best $\overrightarrow{0}$ results were obtained if the plates were only $\frac{C}{0}$ lightly streaked, and well isolated colonies were $\overline{\bar{\rho}}$. obtained, when a clear zone could be seen $\bar{\Phi}$ surrounding the invididual colonies. On a heavily inoculated plate, the whole of the plate ${ }^{\infty}$ may be cleared by some potent proteinase pro- $\overrightarrow{0}$ ducers. The best pigment production is obtained $\overrightarrow{\vec{\omega}}$ by incubating the plates for 24 hours at $37^{\circ} \mathrm{C} \stackrel{\omega}{\omega}$ followed by 24 hours at $20^{\circ} \mathrm{C}$, when many apparently weakly pigmented strains show much enhanced pigment production. All of the $P$.

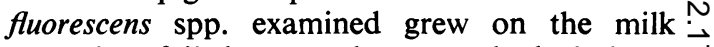
agar, but failed to produce any hydrolysis as demonstrated by clear zones (Figure). Clearly, 웅 any extracellular proteinase they produce is not a caseinase. In addition, nearly all are completely $\vec{z}$ non-pigmented, but a few strains produce yellow pigments after prolonged incubation at low $\stackrel{\bigcirc}{\supset}$ temperatures. $P$. putida produced no hydrolysis $\vec{\varphi}$ or pigment.

Initially in this study the milk powder used to prepare this medium was skim milk powder. This is not easy to sterilize as it will readily caramelize if overheated, and on some occasions does not reconstitute easily, particularly at the $\underset{\mathbb{D}}{\mathbb{D}}$ double-strength concentration necessary for the preparation of the agar. Subsequently Cadbury's $\overline{\vec{O}}$ Marvel granules were used, and this was found 3 easier to use. The latter product was not stated to be thermophil free. Repeated testing of samples has, however, failed to reveal any such 용 organism in this product.

INCREASE IN GROWTH RATE BY INCORPORATION OF NUTRIENT BROTH INTO THE MILK AGAR The addition of less than $10 \%$ broth produced no detectable difference in the results. Concentra- $N$ tions of broth in excess of $25 \%$ tended to mask $N$ the hydrolysis, and in some instances to suppress N pigmentation. At $25 \%$ broth concentration in $\sigma$ the medium both hydrolysis and pigmentation were clearly visible after 24 hours. Therefore if

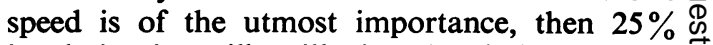
broth in the milk will give the desired result; however, if time is no great concern, then the plain milk agar gives clearer results.

The colony counts showed no significant variation in the number of colonies per plate $( \pm 3.8 \%$; $\mathbf{P}=\mathbf{0 . 0 1 )}$ irrespective of the composition of the agar on which they were grown, the only difference being that not all colonies had completely hydrolysed the milk after 48 hours' incubation

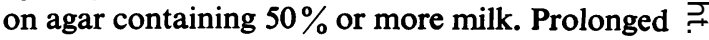
incubation up to a week in no case caused an 


\begin{tabular}{|c|c|c|c|c|c|c|c|c|c|c|c|c|c|}
\hline \multicolumn{2}{|c|}{$\begin{array}{l}\text { Strain } P . \\
\text { aeruginosa }\end{array}$} & \multirow{2}{*}{$\begin{array}{l}\begin{array}{l}\text { Growth } \\
\text { at } 4^{\circ} \mathrm{C}\end{array} \\
-\end{array}$} & \multirow{2}{*}{$\begin{array}{l}\begin{array}{c}\text { Growth } \\
\text { at } 42^{\circ} \mathrm{C}\end{array} \\
+\end{array}$} & \multirow{2}{*}{$\begin{array}{l}\text { Gelatin } \\
\mathrm{G}\end{array}$} & \multirow{2}{*}{$\begin{array}{l}\begin{array}{l}\text { Pyocya- } \\
\text { nin }\end{array} \\
\mathbf{P}\end{array}$} & \multirow{2}{*}{$\begin{array}{l}\begin{array}{l}\text { Aceta- } \\
\text { mide }\end{array} \\
+\end{array}$} & \multirow{2}{*}{$\begin{array}{l}\text { Geraniol } \\
+\end{array}$} & \multirow{2}{*}{$\begin{array}{l}\text { Treha- } \\
\text { lose }\end{array}$} & \multirow{2}{*}{$\begin{array}{l}\text { Inositol } \\
-\end{array}$} & \multirow{2}{*}{ Sucrose } & \multirow{2}{*}{$\begin{array}{l}\text { Benzyl- } \\
\text { amine }\end{array}$} & \multicolumn{2}{|c|}{ Creatine Milk } \\
\hline CST & 651 & & & & & & & & & & & - & $\mathbf{G}, \mathbf{P}, \mathbf{H}$ \\
\hline CST & 652 & - & + & $\mathbf{L}$ & $\mathbf{P}$ & + & + & - & & - & - & - & $\mathbf{G , P , H}$ \\
\hline CST & 653 & - & + & $\mathbf{L}$ & $\mathbf{P}$ & + & + & - & - & - & - & - & $\mathbf{G , P , H}$ \\
\hline CST & 654 & - & + & L & $\mathbf{P}$ & + & + & - & - & - & - & - & $\mathbf{G}, \mathbf{P}, \mathbf{H}$ \\
\hline CST & 655 & - & + & L & $\mathbf{P}$ & + & + & - & - & - & - & - & $\mathbf{G , P , H}$ \\
\hline CST & 656 & - & + & L & $\mathbf{P}$ & + & + & - & - & - & - & - & $\mathbf{G , P , H}$ \\
\hline CST & 657 & - & + & $\mathbf{L}$ & $\mathbf{P}$ & + & + & - & - & - & - & - & $\mathbf{G}, \mathbf{P}, \mathbf{H}$ \\
\hline OSU & 64 & - & + & L & $\mathbf{P}$ & + & + & - & - & - & - & - & $\mathbf{G}, \mathbf{P}, \mathbf{H}$ \\
\hline NCIB & 3756 & - & + & L & - & + & + & - & - & - & - & - & $\mathbf{G}, \mathbf{P}, \mathbf{H}$ \\
\hline NCIB & 5940 & - & + & L & $\mathbf{P}$ & + & + & - & - & - & - & - & $\mathbf{G}, \mathbf{P}, \mathbf{H}$ \\
\hline NCIB & 8248 & - & + & $\mathbf{L}$ & - & + & + & - & - & - & - & - & G,P.H \\
\hline NCIB & 8295 & - & + & L & $\mathbf{P}$ & + & + & - & - & - & - & - & $\mathbf{G}, \mathbf{P}, \mathbf{H}$ \\
\hline NCIB & 8626 & - & + & L & $\mathbf{P}$ & + & + & - & - & - & - & - & $\mathbf{G}, \mathbf{P}, \mathbf{H}$ \\
\hline NCTC & 1999 & - & + & L & $\mathbf{P}$ & + & + & - & - & - & - & - & $\mathbf{G , P , H}$ \\
\hline NCTC & 6750 & - & + & $\mathbf{L}$ & $\mathbf{P}$ & + & + & - & - & - & - & - & $\mathbf{G}, \mathbf{P}, \mathbf{H}$ \\
\hline NCTC & 6751 & - & + & $\mathbf{L}$ & $\mathbf{P}$ & + & + & - & - & - & - & - & $\mathbf{G}, \mathbf{P}, \mathbf{H}$ \\
\hline NCTC & 7244 & - & + & L & $\mathbf{P}$ & + & + & - & - & - & - & - & G,P,H \\
\hline NCTC & 8203 & - & + & L & $\mathbf{P}$ & + & + & - & - & - & - & - & G,P.H \\
\hline NCTC & 8505 & - & + & $\mathbf{L}$ & - & + & + & - & - & - & - & - & $\mathbf{G}, \mathbf{P}, \mathbf{H}$ \\
\hline $\begin{array}{l}\text { Interme } \\
\text { strains }\end{array}$ & diate & & & & & & & & & & & & \\
\hline NCTC & 950 & - & $+?$ & $\mathbf{L}$ ? & - & + & - & + & - & - & - & - & $\mathbf{G , H}$ \\
\hline NCTC & 5940 & - & $+?$ & $\mathbf{L} ?$ & - & + & - & + & - & - & - & - & $\mathbf{G}, \mathbf{H}$ \\
\hline \multicolumn{14}{|c|}{ P. fluorescens } \\
\hline NCIB & 8249 & + & - & - & - & - & - & + & + & + & - & - & G \\
\hline NCIB & 8251 & + & - & - & - & - & - & + & + & + & - & - & G \\
\hline NCIB & 8729 & + & - & $\mathbf{L}$ & - & - & - & + & + & + & - & - & G \\
\hline NCIB & 8865 & + & - & $\mathbf{L}$ & - & - & - & + & + & + & - & - & G \\
\hline NCIB & 8986 & + & - & L & - & - & - & + & - & + & - & - & G \\
\hline NCIB & 9033 & + & - & L & - & - & - & + & + & + & - & - & G \\
\hline NCIB & 9046 & + & - & L & - & - & - & + & + & + & - & - & G \\
\hline NCIB & 9494 & + & - & - & - & - & - & + & + & + & - & - & G \\
\hline NCTC & 8248 & - & + & $\mathbf{L}$ & - & - & + & + & - & - & - & - & G \\
\hline \multicolumn{14}{|c|}{ P. putida } \\
\hline \multirow{2}{*}{\multicolumn{2}{|c|}{$\begin{array}{l}\text { Lab. strain } \\
\text { NCiB } 9034\end{array}$}} & + & - & - & - & + & - & - & - & - & + & + & G \\
\hline & & - & - & - & - & - & - & - & - & - & + & + & G \\
\hline
\end{tabular}

Table III Results of tests for differentiation between the fluorescent aerobic pseudomonads

$+=$ Positive $-=$ Negative $\mathbf{G}=$ Growth $\mathbf{L}=$ Liquefaction $\quad ?=$ slight reaction $\quad \mathbf{P}=$ Pigment $\quad \mathbf{H}=$ Hydrolysis

increase in the number of colonies, but allowed the medium surrounding every colony to clear.

The individual results are summarized in Table III.

\section{Discussion}

From the results presented it can be seen that the pattern of biochemical and other tests for the strains of $\boldsymbol{P}$. aeruginosa, $\boldsymbol{P}$. fluorescens, and $\boldsymbol{P}$. putida tested follow the pattern shown in Table II. In addition it can be seen that where these tests are all positive for $P$. aeruginosa then the growth on the milk agar shows both green pigment and proteinase, confirming the view that these two features alone on this medium are equally reliable as the whole series of biochemical tests for the identification of $P$. aeruginosa.

Likewise it can be shown that when growth is not accompanied by pigment or hydrolysis then the organism is not $\boldsymbol{P}$. aeruginosa, and this is shown by the tests performed on a number of species of $\boldsymbol{P}$. fluorescens and $\boldsymbol{P}$. putida. An interesting point emerges, in that the strains NCIB 3756 and 8248 were received as $P$. fluorescens yet both produced green pigment and hydrolysed the casein in the milk agar. Thus on the basis of this one test these two strains should be renamed $P$. aeruginosa. This is supported by the other bio? chemical tests, which show the typical $P$. aerus ginosa pattern. In addition, phage typing of these two strains gave results that were consistent witP their being $P$. aeruginosa. The remainder of the strains of $P$. fluorescens gave typical results of both biochemical tests and reaction on milk agar? The results for gelatin hydrolysis from $\boldsymbol{P}$. fluores cens agree with those of Cowan and Steed (1965), Wahba and Darell (1965), and Rhodes (1959), in that this character was variable eight out of 11 strains used in this study hydrow lysed gelatin. This is in contrast to the findings of Stanier et al, who observed gelatin liqueo faction in all their strains of $\boldsymbol{P}$. fluorescens. Thi difference is most probably attributable to smalf differences in the composition in the nutrient? gelatin medium and in the length of the incuba $\underset{\mathbb{D}}{\stackrel{P}{0}}$ tion period.

Strains NCTC 950, 5940, 6751, and 8505 were supplied as being examples of poorly pigmented varieties of $P$. aeruginosa. They provide interesting examples of what seem to be in some respectso atypical strains of this organism. As can be clearly seen from the results they fall into two main groups. Strains 6751 and 8505, apart from 
a low production of pigment on normal media, according to all the other biochemical tests showed them to be normal $P$. aeruginosa strains; this was confirmed by the results of the growth on the milk agar, both hydrolysis of the casein and pigment production being observed. In the case of the other two strains, 950 and 5940, the position was not so straightforward. Neither produced pigment on any of the solid media, including the milk agar. They did, however, show some signs of hydrolysis of the casein, and this increased on incubation for a further 48 hours, but no pigment was demonstrable. The results of the biochemical tests likewise showed that these two strains did not conform precisely to the $\boldsymbol{P}$. aeruginosa or the $\boldsymbol{P}$. fluorescens patterns, but in fact have some characters common to both, and these can be regarded as intermediate fluorescens/aeruginosa types. This is supported by the results of the milk agar media previously discussed. Indeed, in view of the recently demonstrated high transformation frequency within the genus Pseudomonas (Khan and Sen, 1967), the existence of such intermediate strains is not surprising. In either case, the milk agar has shown itself to be as reliable as the more conventional biochemical tests.

We wish to thank Dr S. P. Lapage, of the National Collection of Type Cultures, for kindly supplying the poorly pigmented strains of $P$. aeruginosa, and Dr M. T. Parker, of Central Public Health Laboratory, Colindale, London, NW9, for kindly carrying out the phage typing. We also wish to thank The Medical Research Council for a grant which supported part of this work.

\section{References}

Colwell, R. R. (1964). J. gen. Microbiol., 37, 181-194. A study of features used in the diagnosis of Pseudomonas aeruginosa.

Cowan, S. T., and Steel, K. J. (1965). Manual for the Identification of Medical Bacteria. Cambridge University Press, London.

Gaby, W. L., and Free, E. (1953). Occurrence and identification of nonpigmented strains of Pseudomonas aeruginosa in the clinical laboratory. J. Bact., 65, 746.

Gaby, W. L, and Free, E. (1958). Differential diagnosis of Pseudomonas-like microorganisms in the clinical laboratory. J. Bact., 76, 442-444

Haynes, W. C. (1951). Pseudomonas aeruginosa-its characterisation and identification. J. gen. Microbiol., 5, 939-950.

Hugh, R., and Leifson, E. (1953). The taxonomic significance of fermentative versus oxidative metabolism of carbohydrates by various gram negative bacteria. J. Bact., 66, 24-26.

Khan, N. C., and Sen, S. P. (1967). Genetic transformation in Pseudomonas. J. gen. Microbiol., 49, 201-209.

King, E O., Ward, M. K., and Raney, D. E. (1954). Two simple media for the demonstration of pyocyanin and fluorescin. J. Lab. clin. Med., 44, 301-307.

Kovacs, N. (1956). Identification of Pseudomonas pyocyanea by the oxidase reaction. Nature (Lond.), 178, 703.

Lysenko, O. (1961). Pseudomonas-An attempt at a general classification. J. gen. Microbiol., 25, 379-408.

Phillips, I. (1969). Identification of Pseudomonas aeruginosa in the clinical laboratory. J. Med. Microbiol., 2, 9-16.

Preston, N. W., and Morrell, A. (1962). Reproducible results with the gram stain. J. Path. Bact., 84, 241-243.
Rhodes, M. E. (1959). The characterization of Pseudomonas $\Omega$ fluorescens. J. gen. Microbiol., 21, 221-263.

Rhodes M. E., (1961). The characterization of Pseudomonas 7 fluorescens with the aid of an electronic computer. J. gen. Microbiol., 25, 331-345

Rogers, K. B. (1963). Oxidase reaction. (Letter), Lancet, 2, 682. 으

Stanier, R. Y., Palleroni, N. J., and Disudoroff, M. (1966). The aerobic psuedomonads: a taxonomic study. J. gen. Microbiol., 43, 159-271.

Wahba, A. H., and Darell, J. H. (1965). The identification of atypical strains of Pseudomonas aeruginosa. J. gen. 음 Microbiol., 38, 329-342.

\section{Errata}

In Table II in the paper entitled, 'Comparison of quick $\stackrel{\sim}{-}$ and slow thaw methods of producing cryoprecipitate $N$ antihaemophilic factor from fresh and 24-hour-old 음 blood' A. L. Bloom (J. clin. Path., 22, 447-452) the $P$ values for the supernatant have been printed $\vec{Z}$ under the wrong headings. The correct table 'Factor VIII content of cryoprecipitate and supernatant $\frac{\widehat{D}}{\partial}$ plasma', is printed below.

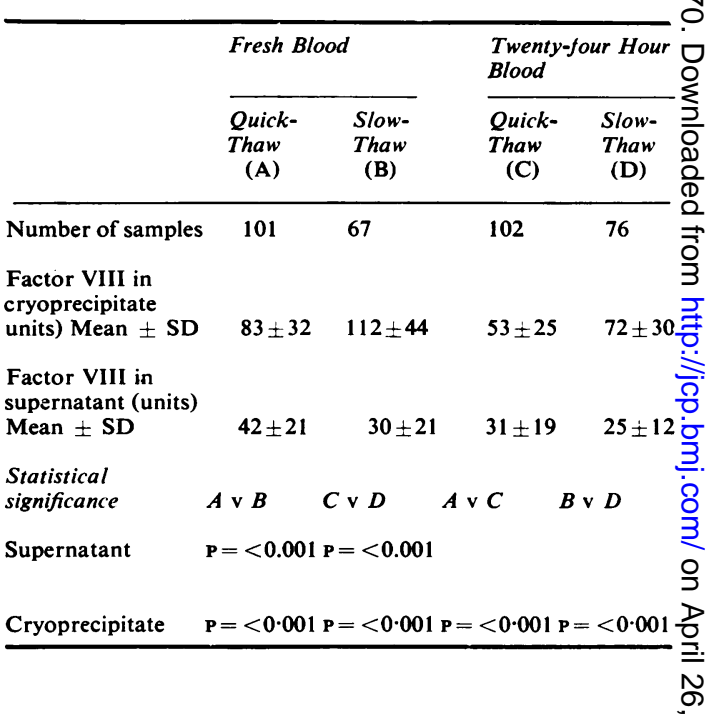

In Table IIa of the paper by Davis et al, J. Clin. N Path., 1969, 22, 634, the figures for Proteus mirabilis under the columns for tetracycline should read:0 S: $9.7 \%$, 'S': $0.9 \%$ and $R: 89.4 \%$; the mean percen-c tages of total should therefore read: S: $30.8 \% ; \frac{C}{\square}$ 'S': $6 \cdot 1 \%$; R: $63 \cdot 1 \%$. 